\title{
Tectonic government in Vietnam: from practice to theory
}

\author{
Viet Hanh $\mathrm{Ho}^{1^{*}}$ \\ ${ }^{1}$ Institute of Social Sciences of the Central Region, Vietnam Academy of Social Sciences No 477, \\ Nguyen Trai Street, Thanh Xuan District, Ha Noi, 10000,Vietnam
}

\begin{abstract}
In recent years, the topic of tectonic government has been in many discussions in Vietnam. From the perspective of inter-industry approach, the paper focuses on analysing the concept of tectonic government in Vietnam, thereby posing a number of theoretical issues such as unifying the concept's understanding, considering its international context and specific conditions in building and operating in Vietnam nowadays. On that basis, the author concludes that from government to tectonic government is not merely a change of name but reflects a renewal of thinking and awareness of the nature and goals towards progressive and mankind civilised values in state governance.
\end{abstract}

\section{The problem setting}

In recent years, the topic of tectonic government has been in many discussions in Vietnam. A number of studies have shown that it has been started from institutional reform, state management perfection to legal system improvement and accountability rising. However, there still exist many different views and inconsistencies about the process formation, concepts and connotations. Therefore, the study of theoretical issues related to tectonic government is critically needed. This paper focuses on analysing some contents related to tectonic government from an inter-industry perspective such as philosophy, politics, public policy, etc. With that approach, we use the comparative method to indicate the context of the concept and the aggregate method to clarify its implications. The research results will contribute to provide some information for teaching and promote further research on the tectonic government, thereby implying some matters to build and operate in Vietnam at the moment and in the future.

\section{Terms and perceptions about tectonic government in Vietnam}

\subsection{The term "tectonic government"}

In the current process of awareness and practice, the contents related to the construction and operation of tectonic government have a series of theoretical issues. One of the most

\footnotetext{
*Corresponding author: hanhcjs@yahoo.com
} 
important theoretical issues that need to be sorted out is how to interpret "tectonic government" unanimously. Currently, there are many different understandings about this concept in the academic world. This is shown in the process of translating from Vietnamese to English. Some have used the phrase Constructive government in English to express the understanding of tectonic government. With this interpretation, it is possible to highlight its features as a constructive government during operation and development. However, it has not yet illustrated the creativity of the tectonic government. Therefore, there is another opinion to use Creative government to emphasise the creativity. Additionally, many scholars in Vietnam agree that Developmental government is the right interpretation based on Chalmers Johnson's suggestion about the developmental government and developmental state. Accordingly, Chalmers Johnson realised that there are three models of government: Regulated government (governments of countries following the free market model); centralised bureaucratic planning (governments deny the role of markets) and developmental governments (governments of countries value market's role, not at absolute level, but actively intervene to guide the market). Also according to Chaimers's perception, the developmental government is in the middle of regulated government model and centralised bureaucratic planning one. It can be seen that the concepts have been more or less related to specific aspects of tectonic government. Some scholars have proposed to combine the English words "tectonic" and "government" into tectonic government to elaborate on the concept. We also think that the term tectonic government is an appropriate expression. Although the word tectonic is used geographically, it has the root meaning to describe the process that governs the structure and characteristics of the Earth's crust and its evolution over time, such as mountain tectonics, tectonic continental core, etc. The term is expressed in accordance with the process of construction and operation associated with the characteristics, nature, goals and motivations of the government. Hence the word "tectonic government" outlines the process that governs the structure, including inside and outside the building and operating process of the government. However, the expressions do not reflect the nature, objectives and motivation, as well as the structure of the tectonic government. In our opinion, these terms have not fully expressed the nature and connotation of the tectonic government because the concept has not appeared yet, so we cannot try to find a new term to describe. If possible, the term tectonic government should be used as the policy term Doi moi. As a result, if the term tectonic government is translated from Vietnamese into English, it should be Kien tao government with new ideas in building and operating in Vietnam nowadays.

\subsection{Awareness of Kien tao government in Vietnam}

Currently, in Vietnam there are many different and divided interpretations about the concept's origin, view and connotations. In general, the scholars constructing the concept on four main aspects: (1) The Kien tao government, the tectonic state that has been used in the world from Europe to Asia, or appeared in Asia before; (2) Opinions arguing about the need to distinguish the tectonic state and the Kien tao government. Even in this opinion, there are scholars who believe that there is no so-called Kien tao government but only tectonic state; (3) Another thread of opinion is that the Kien tao government is identical to the tectonic state. Here, the Kien tao government is viewed at the level of showing the state's intervention in different areas of social life, especially in the economy; (4) Opinions explain the terminology is a product of Vietnam itself, of the Prime Minister of Vietnam. This idea holds that some Kien tao government implications may be included in the discussion of this subject as well as the operating practices of governments around the world. However, the Kien tao government in Vietnam is a generalisation based on the operational practices of the Vietnamese government from central to local levels in terms of 
proceeding to socialism under the absolute and comprehensive leadership of the Communist Party in a new context. This is our point of view in constructing a Kien tao government in Vietnam today.

\subsection{The process of developing the concept of Kien tao government in Vietnam}

The opinion of Kien tao government was created by Prime Minister Nguyen Xuan Phuc, immediately after his taking office as Prime Minister for the 2016-2021 term. In 2016, Prime Minister Nguyen Xuan Phuc presented the key tasks of the government term, including the task of constructing a Kien tao government. Accordingly, the objectives and tasks of the Kien tao government are: "The Government creates Kien tao development, integrity, strong action to serve the people". After that, the concept of Kien tao government was created and supplemented by the head of the government in the process of executing tasks in practical activities. In the direct questioning session on the parliament (afternoon of $18^{\text {th }}$ Nov 2017), for the first time, the Prime Minister himself stated his views before the National Assembly forum and shared the definition of Kien tao government:

- The government proactively designs a good legal system, good policies and good institutions to nurture a developed economy, rather than passively cope with actual happenings.

- The state does not change the market, where the market can do it, private enterprises can do it, the State does not intervene, but instead creates conditions for businesses to do. The state will only invest in areas where private enterprises cannot invest.

- The government must establish a favorable business environment, not only leading among ASEAN countries, but also striving to reach the criteria of OECD group.

- The government must also talk with action, tighten discipline, especially to replace officials who do not meet the job requirements, build e-government, e-commerce to electronic courts, etc. All of these are important factors to build a tectonic government.

In the Parliament, the Prime Minister also clarified the difference between Kien tao government and executive government: the former is more proactive in building institutions and laws, not just act on what is available by law. The government apparatus must be more active, have more initiatives, study the surrounding world more to apply along with the Party's guidelines and policies to be more proactive and not passive.

Thus, the opinion of Kien tao government comes from the actual operational process, which also means that the implications of the construction and operation of the created government are constantly being supplemented and perfected during the cognitive processes and executive practices. This process shows the close relationship between theory and practice.

First of all, one of the important contents of Kien tao government is that the government designs a system of laws, policies and institutions to nurture the economy, not to deal with the happenings passively. Through the administration practice of the government, that content is constantly supplemented, attached to the requirement of the improvement of institutions, policies and laws. It can start from administrative procedure reform, business investment environment improvement to apparatus perfection, state discipline raising, etc. In 2016, the government issued important instructions in creating institutions for Kien tao government: "Main aspects are improving institutions, promoting administrative procedure reform, refining business and investment environment and enhancing competitiveness. The government is determined to build its integrity, development and service to people and businesses; promulgating detail document and guiding the law implementation". Additionally, building institutions must also meet the requirements of constructing administrative discipline, fighting against corruption, wastefulness and group interests. In 
2017, when summarizing the socio-economic situation of the year, the Prime Minister pointed out these requirements, which are: "Strengthening discipline, administrative discipline, promoting the responsibility of the head, drastically directing towards the government of integrity, development and action to the people; preventing and fighting against corruption, wastefulness and group interests". Besides, the process of perfecting the institutions, policies and laws of the Kien tao government also goes along with consolidating the entire system towards streamlining the efficiency and effectiveness. According to the Prime Minister, creating a Kien tao government needs to address the goals of building the State apparatus: "Consolidating the organisational structure, reducing the focal points, payroll, ensuring democracy, public, transparency, professionalism, effectiveness in the spirit of building a Kien tao administrative system to serve the people". Kien tao government is considered a driving force for development in Vietnam. The government has continuously built a unified, effective administrative system that is wellimplemented in creating tasks with integrity to act and serve the people and businesses.

Secondly, creating a business environment that serves the people and businesses is a throughout viewpoint in building and operating a Kien tao government. The content was clarified and supplemented by the Prime Minister with specific views from creating a startup environment, improving competitiveness to corporate culture, etc. This is one of the most important functions internally in constructing a Kien tao government. Since the election of Prime Minister, creating a start-up environment has become one of the requirements in the process of operating the government. According to the head of the government, starting a business is "one of the success measures of Kien tao government". The Prime Minister also emphasised Kien tao interaction and services in Kien tao government as the factor in creating a start-up environment. The head of the government said: "Promoting start-ups, creating favorable conditions for businesses to grow and succeed are the driving force for the socio-economic development of the country. The tectonic interaction and service become the foundation in the relationship between the government and businesses". Additionally, Kien tao government also meets the requirements of accompanying and serving enterprises in ensuring intellectual property rights for sustainable development. According to the Prime Minister, the government needs to create "a favorable investment environment, protect property rights and intellectual property rights and above all, join hands with businesses to carry out these important tasks". To meet that requirement, Kien tao government must meet the business activities of investors and community: "The government creates with integrity and serves to build and ensure the good, friendly, highly competitive business environment; not only free to conduct business but also safe for investors, business, assets and investment capital; not only low transaction costs but also low risks; not only controlled monopoly but also effectively combat fake and counterfeit goods to ensure a fair and efficient business environment; Investors and businesses are not only respected but also honored; The business environment has high reliability and solidity so that people can be assured to invest and expand business. We must innovate, reform, develop ourselves in the trend, in the business and investment environment set by the government, to create conditions for businesses and economic sectors to develop in Vietnam".

Kien tao government has also been expanded with a new connotation, namely that it must do a good role in innovation, clearly shape the corporate culture, with the core values for global competitiveness. According to the Prime Minister, the role of the government in innovation is to create a learning and creative environment: "A constantly learning and creative society is the ideal environment for development and an important driving force to promote the construction and action of Kien tao government". Additionally, the role of the government in creating a clear corporate culture, with a core value to global competitiveness, is one of the urgent requirements. According to the Prime Minister: "A 
good brand is not only the property of the business but also a national property. Every country strives to protect its brands. That is why Kien tao government is very interested in the topic of corporate culture, business culture and entrepreneurial morality, etc. Building corporate culture is about building competitiveness and trade advantages, Vietnam's identity in globalised economy in the $21^{\text {st }}$ century. It must be part of the task of Kien tao government, of Vietnamese business community. It must be an inseparable part for the goal of building Vietnam into a start-up nation".

Additionally, in the Prime Minister's view, Kien tao government in Vietnam needs to construct a business environment towards international criteria "not only topping the ASEAN group but also striving to reach the ones of OECD countries". In that regard, the government needs to ensure the property protection and intellectual property rights so that businesses can be secured of production and business, namely: "The Government endeavors to create environmental favorable investment environment, protection of property and intellectual property rights, join hands to work with businesses to carry out this important task". Moreover, the government needs to create an environment for investment and international integration to participate in global value chains and ensure sustainability. According to the Prime Minister, "The Kien tao government that Vietnam is constructing means a balance between economic stimulus policies and the management of resource scarcity and environmental sustainability".

Thirdly, the government must talk the talk and walk the walk, tightening discipline, especially to by immediately replacing officials who do not meet the job requirements. Egovernment, e-commerce and electronic courts, etc. are all needed to be planned out. These are important factors to build a Kien tao government. These also can be firstly expressed by building a clean, integrity, actionable and constructivist government for development: "focusing on building an integrity, Kien tao government with strong action, syncing speaking with action to serve people and businesses". Through the administration of the Prime Minister, those contents are concretised in many fields but each content must be actionable. During the first year of the Prime Minister, the government implemented actions on Kien tao government and achieved some results with determination to build the Kien tao government: "Complete improving institutions, accelerate administrative procedure reform, improve business and investment environment and enhance competitiveness, determine to build an integrity, Kien tao government serving people and businesses; promulgate documents with details and guidance for implementation of laws, especially investment and enterprise law; lowest number of outstanding documents compared to the same period of many years. The government also focuses on implementing administrative procedure reform in 2016; promulgates Resolution 19 on improving the business investment environment, enhancing competitiveness, Resolution 60 on speeding up the disbursement progress for public investment projects and directing branches for urgent implementation".

Additionally, one of the most important tasks in the construction of the Kien tao government is to enable capable staff to adapt to the current scientific and technological revolution: "The Kien tao government that Vietnam needs to pay special attention to is to improve human resources quality in accordance with the reality of the 4.0 industrial revolution".

Thus, Kien tao government is a requirement stemming from the reality in building and operating in the economic - political institution in Vietnam. The Vietnamese Government has continuously sought theoretical awareness and practical summaries to develop new thinking in the government building process. That also raises theoretical and practical issues in the process in our country nowadays. 


\section{Some issues raised in Kien tao government construction and operation in Vietnam nowadays}

In the awareness process of Kien tao government, we need to pay attention to some subjective and objective requirements of reality in the process of constructing and operating Kien tao government:

Firstly, the construction and operation of Kien tao government sets out not only at the central government level but also at the local one. The local government plays a very important role in building and operating Kien tao government because this is the most direct mechanism for managing the policies implementation. It also means that many practical and theoretical issues on the process of organizing and implementing policies need to be paid more attention in order to promote the role of local government. The local government apparatus at all levels needs to be more proactive in renewing the way of leadership, management and governance to improve policy adaptive capacity and respond to changes nationally and internationally, so that we can ensure the fast and sustainable development of each locality. Therefore, local authorities need to have awareness and change in the operation process. It also requires special attention to train and foster people in the apparatus - people are central and decisive to the success of the of building and operating to institutional construction, innovation, administration, reforming, etc.

Secondly, Vietnam's political regime is quite specific compared to the political institutions of other countries in the world. The Communist Party of Vietnam plays a very important role in leading the government. The role of the Communist Party of Vietnam is stipulated in Article 4 of the Constitution of the Socialist Republic of Vietnam (2013). Accordingly, the Party is the leading force of the state and society. The role of the Party is not independent but harmonised in the power apparatus by the party organisations and its members operating within the framework of the Constitution and laws. The government entities themselves operate according to the Party's principles. Therefore, the matter of clarifying the role and promoting the role of party committees is one of the very important issues in the construction and operation of the Kien tao government.

Thirdly, the international context and specific conditions in Vietnam are one of the theoretical issues that needs to be considered in studying while building and operating the current Kien tao government.

In the context of international integration and globalisation, its impact is increasingly having profound impacts on each entity of social life in general and in building and operating the Kien tao government in particular. The trend of international integration and global process is becoming a mainstream trend in international relations. The development of each nation cannot be separated from that objective requirement. The process also requires the government to have adaptive capacity and active participation with entities and standards in international relations. Moreover, international integration and globalisation also lead to global competition with complicated and unpredictable happenings, creating both opportunities and challenges and posing extremely urgent requirements at the same time. Therefore, it is required that the government entities not only actively participate, but also reform and innovate in the way of leadership and management to improve policy adaptive capacity before changes, aiming to ensure the country's rapid and sustainable development.

Today, the 4.0 revolution is imposing urgent requirements on the development of each nation. In particular, the application of artificial intelligence, information technology and the use of digital platforms has an increasingly profound influence on all aspects of social life. Therefore, it has important influence on the formulation and operation of state policy implementation. Encouraging application and promotion artificial intelligence, information technology and digital technology's achievements in building and operating the Kien tao 
government is one of the important tasks to contribute to improve the ability of competitiveness, optimise the management, use and exploit effectively the process of innovation in our country.

\section{Conclusion}

It can be said that the concept of Kien tao government is a profound cognitive process between awareness and practice, as well as acquiring and inheriting the essence of state governance in managing the government to adapt to the international context and specific conditions in Vietnam today. Therefore, from the government to the Kien tao government is not simply a change of name but hidden behind them are different connotations and meanings, reflecting the process of thinking innovation and awareness of nature and items, towards progressive and civilised values of mankind in state governance. The theoretical and practical issues related to the Kien tao government need more attention from researchers and managers in order to build and operate it effectively.

\section{References}

1. C. Johnson, MITI and the Japanese miracle, Stanford, Stanford University Press, CA (1982).

2. A. K. Bagchi, The Developmental State in History and in the Twentieth Century, Regency Publications (2004)

3. H.-J. Chang, 'How to 'do' a developmental state: Political, organizational, and human resource requirements for the developmental state”, in: O. Edigheji (ed.), Constructing a democratic developmental state in South Africa - Potentials and challenges, Human Science R. (2010)

4. A. Martin, Australian Journal of Political Science, 46, 243-256, (2011). doi.org/10.1080/10361146.2011.567971

5. B. D. Phong, Dantri review. July, 23, 2018 (2018).

6. V. C. Giao, State organization journal, 30, 35-40 (2017).

7. T. Q. Dong, Dantri review. August, 27, 2016 (2016).

8. L. Q. Ly, Review of Finance. October 23, 2017 (2017).

9. H. Tra, Vietnam Economic Times, August 18, 2017 (2017).

10. The Prime Minister of Vietnam, Parliament speech, Hanoi (2017). The Prime Minister of Vietnam, Speech at Vietnam Enterprise Forum 2016, Hanoi (2016).

11. The Prime Minister, Prime Minister launched the building of corporate culture (2016).

12. The Prime Minister of Vietnam, Globalization is still the inevitable trend, Hanoi, (2017).

13. The Prime Minister of Vietnam, Report on socio-economic situation in the first 6 months and major tasks and solutions for the last 6 months of 2016, Hanoi, (2016). 